\title{
Acute vasoreactivity testing predicts outcome of idiopathic pulmonary arterial hypertension patients with a negative acute response
}

\author{
Yuanyuan Sun ${ }^{1 \#}$, Yuan Li ${ }^{1 \#}$, Xiangrui Meng ${ }^{2 *}$, Rong Jiang ${ }^{1}$, Qinhua Zhao ${ }^{1}$, Lan Wang ${ }^{1}$, Lingzi Shi ${ }^{3}$, \\ Cijun Luo ${ }^{1}$, Hongling Qiu ${ }^{1}$, Wenhui $\mathrm{Wu}^{1}$, Jinling $\mathrm{Li}^{1}$, Jing $\mathrm{He}^{1}$, Jinming Liu ${ }^{1}$, Ping Yuan ${ }^{1}$, Sugang Gong ${ }^{1}$ \\ ${ }^{1}$ Department of Cardio-Pulmonary Circulation, Shanghai Pulmonary Hospital, Tongji University, School of Medicine, Shanghai, China; ${ }^{2}$ Institute of \\ Bismuth Science, University of Shanghai for Science and Technology, China; ${ }^{3}$ School of Clinical Medicine, Hebei Medical University, Shijiazhuang, \\ China \\ Contributions: (I) Conception and design: J Liu, P Yuan, S Gong; (II) Administrative support: None; (III) Provision of study materials or patients: \\ None; (IV) Collection and assembly of data: Y Sun, Y Li, X Meng, R Jiang, Q Zhao, L Wang, L Shi, C Luo, H Qiu, W Wu, J Li, J He; (V) Data \\ analysis and interpretation: Y Sun, Y Li; (VI) Manuscript writing: All authors; (VII) Final approval of manuscript: All authors. \\ "These authors contributed equally to this work. \\ Correspondence to: Jinming Liu, MD; Yuan Ping, MD; Sugang Gong, MD. Department of Cardio-Pulmonary Circulation, Shanghai Pulmonary \\ Hospital Affiliated to Tongji University, No. 507 Zhengmin Road, Shanghai 200433, China. \\ Email: jinmingliu@tongji.edu.cn; pandyyuan@tongji.edu.cn; gongsugang1999@sohu.com.
}

\begin{abstract}
Background: Acute vasoreactivity testing (AVT) during right heart catheterization (RHC) is performed in certain subsets of patients with pulmonary arterial hypertension $(\mathrm{PAH})$ in order to identify those who benefit from calcium channel blockers. The present study aimed to investigate the prognostic value of pre-AVT, post-AVT, and changes in AVT ( $\triangle \mathrm{AVT}$ ) parameters for idiopathic PAH (IPAH) patients with a negative acute response, and to identify sex differences that could be of prognostic value.

Methods: A total of 487 incident IPAH patients (171 males and 316 females) with a negative acute response to AVT were recruited from Shanghai Pulmonary Hospital between 2009 and 2018. Outcomes were predicted using the Kaplan-Meier curve and univariate/multivariate Cox regression analyses. All patients were followed up till January 2020, with outcome specified as all-cause mortality.

Results: Inhalation of iloprost aerosol improved the hemodynamic parameters for all patients. PostPVR was decreased, and post-cardiac output (post-CO) and post-cardiac index (post-CI) were increased compared with pre-AVT parameters among males. Increased post- artery oxygen saturation (post-SaO $\mathrm{S}_{2}$ and decreased post-mean right atrium pressure (post-mRAP) were also observed in females. For all patients, pre-CO $\geq 3.25 \mathrm{~L} / \mathrm{min}$, post-mPAP $<53 \mathrm{mmHg}$, and post-mixed venous oxygen saturation (post-SvO ${ }_{2} \leq 63 \%$ were parameters suggesting better prognosis. For males, patients with pre-PVR $<12.47$ Wood units, pre$\mathrm{SvO}_{2} \geq 64 \%$, and post-mean pulmonary artery pressure (post-mPAP) $<51 \mathrm{mmHg}$ had a better prognosis. For females, patients with $\triangle \mathrm{mPAP} \geq-4 \mathrm{mmHg}$ and $\triangle \mathrm{PVR} \geq-0.25$ Wood units had better outcomes.

Conclusions: AVT parameters, including pre-AVT, post-AVT and $\triangle \mathrm{AVT}$, have a more important prognostic value than currently used for identify a small subgroup of patients with PAH who are suitable for high-dose calcium channel blockers. Sex differences in AVT parameters suggest that sex should be taken into account in estimating prognosis.
\end{abstract}

Keywords: Idiopathic pulmonary arterial hypertension (IPAH); acute vasoreactivity testing (AVT); hemodynamics; sex differences; prognosis

Submitted Oct 12, 2020. Accepted for publication Dec 13, 2020.

doi: $10.21037 /$ atm-20-7339

View this article at: http://dx.doi.org/10.21037/atm-20-7339 


\section{Introduction}

Idiopathic pulmonary arterial hypertension (IPAH) is a progressive, devastating, and incurable disease characterized by structural changes to the small pulmonary arteries, which lead to increased pulmonary vascular resistance (PVR) ultimately resulting in right heart failure and death $(1,2)$. Right heart catheterization (RHC) remains the gold standard procedure to confirm the diagnosis of pulmonary hypertension ( $\mathrm{PH}$ ) (3). Acute vasoreactivity testing (AVT) is an additional examination to identify of patients suitable for high-dose calcium channel blocker (CCB) treatment is recommended only for patients with idiopathic PAH (IPAH), heritable PAH) or drug-induced PAH (4). AVT should be completed during the first RHC. A positive acute response is defined as a reduction of the mean pulmonary arterial pressure (mPAP) $\geq 10 \mathrm{mmHg}$ and the absolute value of $\mathrm{mPAP} \leq 40 \mathrm{mmHg}$ with an increased or unchanged cardiac output (CO) (4). Although this positive acute response is found in less than $10 \%$ of patients with such a deadly progressive disease, it has important clinical significance in both the diagnosis and treatment of these patients (5).

In 2015, Leuchte et al. (6) reported that changes in PVR ( $\triangle$ PVR) during AVT were of prognostic relevance for 66 patients with IPAH who presented with a negative acute response. They found that post-CO, post-cardiac index (CI), and post- mixed venous oxygen saturation $\left(\mathrm{SvO}_{2}\right)$ parameters were increased, while post-mPAP and post-PVR parameters were decreased after AVT, but the prognostic value of these parameters was not further explored. Recently, our center conducted two studies on evaluating the prognostic value of pre-AVT, post-AVT and changed AVT $(\triangle \mathrm{AVT})$ parameters in patients with chronic thromboembolic pulmonary hypertension (CTEPH) $(7,8)$. One study found that pre-mixed venous oxygen saturation (pre-SvO $\mathrm{S}_{2}$ ), post-PVR, and $\triangle \mathrm{PVR} / \mathrm{PVR}$ could be used as independent parameters to predict outcomes of patients with CTEPH (7). The other study demonstrated that a mean right atrial pressure $(\mathrm{mRAP}) \geq 8.0 \mathrm{mmHg}$ and $\mathrm{SvO}_{2}$ $\leq 61.8 \%$ both pre-AVT and post-AVT were independent predictors of event-free survival for females with CTEPH, whereas $\Delta \mathrm{SvO}_{2} \leq 0.6$ was an independent predictor of eventfree survival for males with CTEPH (8). These suggest that different hemodynamic parameters during the AVT have discrete prognostic values for both sexes (8).

Based on the above findings, the present study aimed to investigate whether pre-AVT, post-AVT, and $\triangle \mathrm{AVT}$ parameters have prognostic value for IPAH patients with a negative acute response, and whether the sex difference in AVT parameters provides more hemodynamic information for patients with IPAH.

We present the following article in accordance with the REMARK reporting checklist (available at http://dx.doi. org/10.21037/atm-20-7339).

\section{Methods}

\section{Study design and participants}

A total of 487 patients (171 males and 316 females) with incident IPAH were enrolled at Shanghai Pulmonary Hospital between February 2009 and September 2019. A diagnosis of IPAH was defined as $\mathrm{mPAP} \geq 25 \mathrm{mmHg}$, pulmonary capillary wedge pressure (PCWP) $\leq 15 \mathrm{mmHg}$, and PVR $>3$ Wood units as measured by RHC in accordance with the European Society of Cardiology (ESC) guidelines $(3,9)$. Exclusion criteria were as follows: (I) $\mathrm{PH}$ associated with anorexigens, connective tissue diseases, congenital heart diseases, portal hypertension, or HIV infection; (II) other chronic respiratory diseases; (III) patients with a negative acute response (9) during RHC; (IV) patients with acute or chronic illnesses that might affect hormonal metabolism (i.e., acute or chronic infections, chronic autoimmune diseases, and previously established primary endocrine disorders) and patients receiving any treatment with hormones (anabolic steroids, thyroid hormones, and corticosteroids) or drugs that significantly inhibit hormone production, either at the time of the study or in the past $(4,10,11)$.

This study complied with the Declaration of Helsinki (as revised in 2013) and was approved by the Medical Ethics Committee of Shanghai Pulmonary Hospital. Written informed consent was obtained from either the patients or their next of kin.

\section{RHC and AVT assessment}

None of the patients were receiving any PAH therapies at the time of the RHC. An 8F introducer sheath (St Jude Medical Inc., MN, USA) was placed in the right internal jugular vein or the right subclavian vein, and a quadric-lumen $7 \mathrm{~F}$ Swan-Ganz catheter (Edwards Lifesciences, Irvine, CA, USA) was inserted into the pulmonary artery. The correct positioning of the catheter was verified by chest fluoroscopy. The mPAP, mRAP, and PCWP parameters were measured 
at baseline and after vasodilator administration. The $\mathrm{CO}$ was measured in triplicate using the thermodilution technique (Edwards Lifesciences) with an ice-cold isotonic sodium chloride solution. PVR was calculated as (mPAP PCWP)/CO. Heart rate (HR), electrocardiogram, systemic arterial pressure, and oxygen saturation were measured continuously. In addition, arterial blood gases and $\mathrm{SvO}_{2}$ were measured (ABL 555; Radiometer, Copenhagen, Denmark) (12).

After a stable baseline period of at least 20 minutes, each patient was asked to inhale $5 \mathrm{mg}$ of iloprost (Ventavis, BayerVital, Germany) via a mouthpiece for a duration of approximately 15 minutes. The hemodynamic parameters were measured immediately after the iloprost inhalation ended and 15 minutes after the end of the aerosolization period when the maximal response was recorded.

\section{Targeted therapies}

Three well-known pathways contribute to the pathogenesis of $\mathrm{PAH}$ : the endothelin, $\mathrm{NO}$ and prostacyclin pathways. Based on the three pathways, more than ten targeted drugs have been applied in clinical practice, including endothelin receptor antagonists (ambrisentan, bosentan and macitentan), phosphodiesterase type 5 inhibitors and guanylate cyclase stimulators (sildenafil, tadalafil and riociguat) and prostacyclin analogues and prostacyclin receptor agonists (Berapros and epoprostenol). In our center, physicians will decide whether to use a single target drug or a combination therapy for IPAH patients with negative vascular response test.

\section{Follow-up of patients}

Follow-up intervals were determined by physicians based on the individual patient's healthcare needs. Patients with IPAH were encouraged to visit our outpatient department or to phone us every 3-6 months according to the ESC guidelines. The outcome was all-cause mortality. Survival rate was estimated from the date of diagnosis to 5 th January, 2020.

\section{Statistical analysis}

Results were expressed as mean \pm standard deviation (SD) or median and interquartile range (IQR) for continuous variables and as percentages (\%) for categorical variables. Comparison of the clinical characteristics between patients was performed using the Chi-square test for categorical data and the Student's $t$ test or Mann-Whitney $U$ test for continuous data. The impact of parameters on prognosis was evaluated using univariate and multivariate Cox proportional hazards analyses. Age and body surface area (BSA) were forced into models to adjust the multivariate analysis. A receiver operating characteristic (ROC) analysis was used to determine the area under the curve (AUC) for continuous variables identified from the multivariate regression analysis, and optimal cut points were determined by the value which results in the maximum sum of sensitivity and specificity. Survival curves were derived using the Kaplan-Meier method and were compared using the log-rank test.

All statistical analyses were performed using SPSS (Statistical Package for the Social Sciences, Chicago, IL, USA) software version 25.0 and GraphPad Prism (San Diego, CA, USA) version 8.0.

\section{Results}

\section{Baseline characteristics}

Clinical characteristics, results of laboratory tests, parameters of pre-AVT, and targeted therapies are shown in Table 1. The mean ages of 171 males and 316 females with IPAH were $41.08 \pm 20.60$ and $36.68 \pm 15.49$ years, respectively. Both age and BSA were significantly higher in males than in females. No significant differences were found between males and females in the 6-minute walking distance $(6 \mathrm{MWD})$ test, the World Health Organization Functional Classification (WHO-FC) system, and the levels of N-terminal pro-brain natriuretic peptide (NTproBNP). There was no significant difference in the use of medications between male and female patients.

\section{Comparison of pre-AVT bemodynamic parameters}

The pre-mean PCWP (pre-mPCWP) and pre-artery oxygen saturation (pre- $\mathrm{SaO}_{2}$ ) indices were higher in males than in females. The pre-mRAP, pre-mPAP, pre$\mathrm{PVR}$, pre-CO, pre-cardiac index (pre-CI), and pre$\mathrm{SvO}_{2}$ parameters did not show any significant difference between male and female patients (Table 1). The levels of pre-mRAP, pre-mPAP, pre-mPCWP, and pre-PVR were significantly higher in non-survivors than in survivors for all patients, and pre-CO, pre-CI, and pre- $\mathrm{SvO}_{2}$, indices were significantly lower in non-survivors than in survivors 
Table 1 Baseline characteristics and hemodynamics of patients with IPAH $(\mathrm{n}=487)$

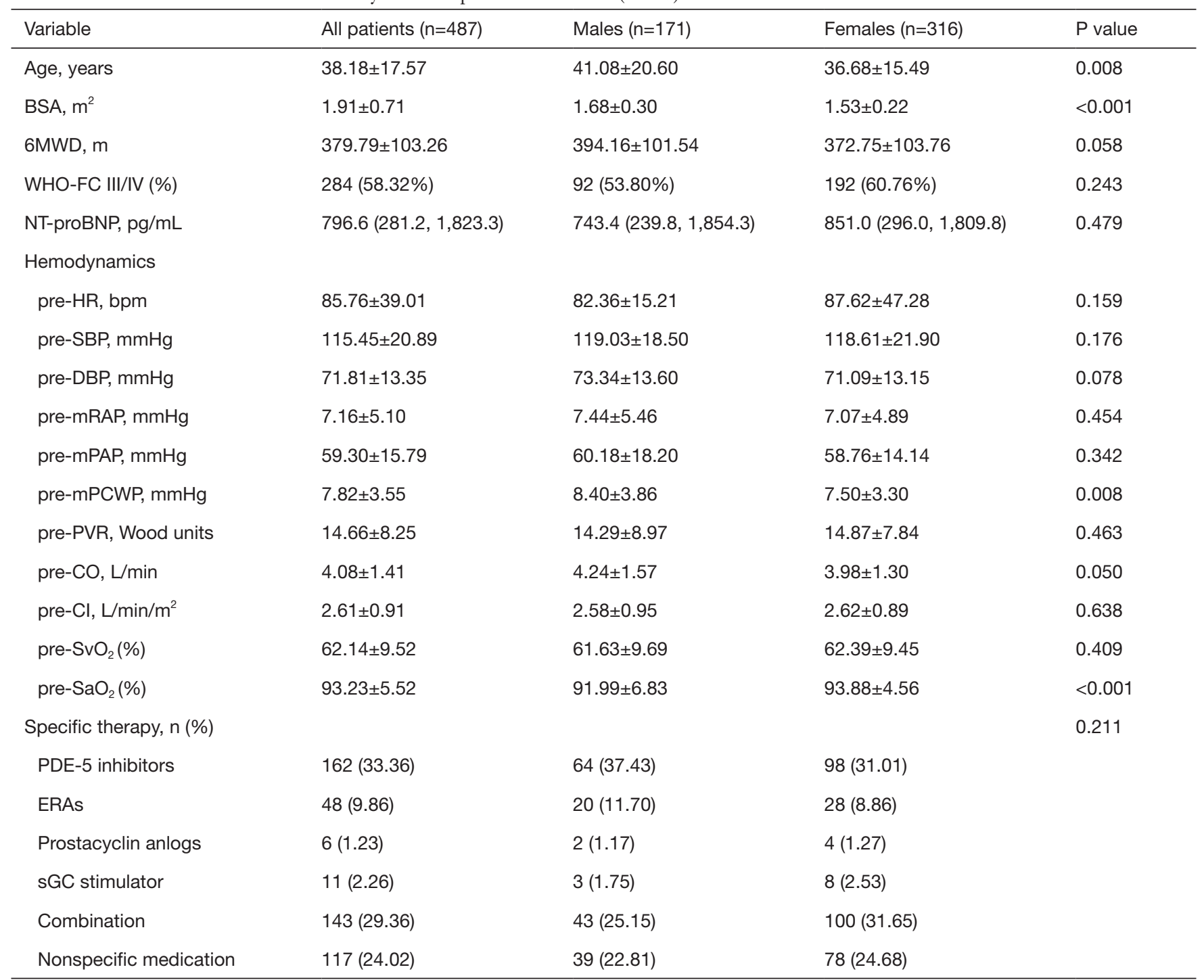

6MWD, 6-minute walk distance; BSA, body surface area; Cl, cardiac index; CO, cardiac output; DBP, diastolic blood pressure; ERA, endothelin receptor antagonist; HR, heart rate; mPAP, mean pulmonary arterial pressure; mPCWP, mean pulmonary capillary wedge pressure; mRAP, mean right atrial pressure; NT-proBNP, N-terminal pro-brain natriuretic peptide; PDE-5, phosphodiesterase 5; PVR, pulmonary vascular resistance; SBP, systolic blood pressure; SGC, soluble guanylate cyclase; $\mathrm{SvO}_{2}$, mixed venous oxygen saturation; $\mathrm{SaO}_{2}$, artery oxygen saturation; WHO-FC, World Health Organization functional classification.

(Figure 1). We also compared sex differences in preAVT parameters between survivors and non-survivors. Interestingly, the pre-mPCWP level was higher in male non-survivors than in female non-survivors (Figure 1C). However, pre-CO was higher and pre- $\mathrm{SaO}_{2}$ was lower in male survivors than in female survivors (Figure $1 E, H$ ). Pre$\mathrm{SaO}_{2}$ was also lower in male non-survivors than in female non-survivors (Figure 1H).

\section{Comparison of post-AVT bemodynamic parameters}

The parameters of post-AVT were measured 15 minutes after inhaling the iloprost aerosol, and it was found that post-CO was higher and post- $\mathrm{SaO}_{2}$ was lower in male patients than in female patients. However, there was no significant difference in other parameters of post-AVT between male and female patients (Table 2). The levels of 

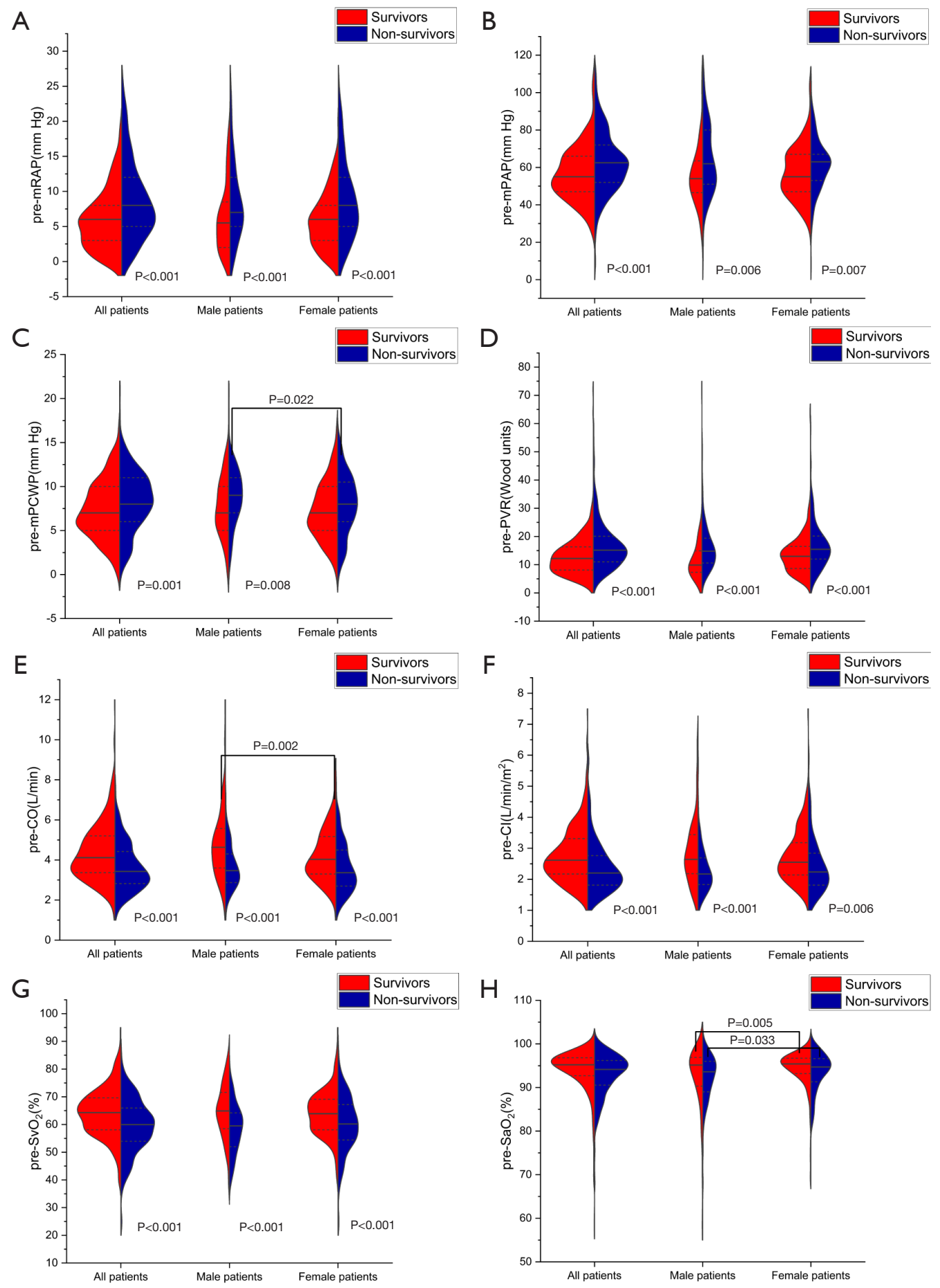

Figure 1 Comparison of the parameters of pre-AVT between survivors and non-survivors. (A) Comparison of pre-mRAP between survivors and non-survivors; (B) comparison of pre-mPAP between survivors and non-survivors; (C) comparison of pre-mPCWP between survivors and non-survivors; (D) comparison of pre-PVR between survivors and non-survivors; (E) comparison of pre-CO between survivors and nonsurvivors; (F) comparison of pre-CI between survivors and non-survivors; (G) comparison of pre-SvO $\mathrm{O}_{2}$ between survivors and non-survivors; $(\mathrm{H})$ comparison of pre- $\mathrm{SaO}_{2}$ between survivors and non-survivors. AVT, acute vasoreactivity testing; mRAP, mean right atrial pressure; mPCWP, mean pulmonary capillary wedge pressure; PVR, pulmonary vascular resistance; CO, cardiac output; CI, cardiac index; SvO ${ }_{2}$, mixed venous oxygen saturation; $\mathrm{SaO}_{2}$, artery oxygen saturation. 
Table 2 Patient hemodynamic response to a single dose of $5 \mathrm{mg}$ iloprost aerosol

\begin{tabular}{lccc}
\hline Variable & All patients $(\mathrm{n}=487)$ & Males $(\mathrm{n}=171)$ & Females $(\mathrm{n}=316)$ \\
\hline Post-HR, bpm & $84.63 \pm 18.07$ & $84.01 \pm 17.43$ & $84.94 \pm 18.41$ \\
Post-SBP, mmHg value & $116.73 \pm 17.55$ & $118.96 \pm 20.62$ \\
Post-DBP, mmHg & $111.58 \pm 19.96$ & $70.76 \pm 12.76$ & $69.40 \pm 13.76$ \\
Post-mRAP, mmHg & $68.54 \pm 13.51$ & $6.94 \pm 5.35$ & $6.76 \pm 4.96$ \\
Post-mPAP, mmHg & $6.82 \pm 5.09$ & $56.17 \pm 19.22$ & 0.113 \\
Post-mPCWP, mmHg & $55.17 \pm 16.71$ & $8.46 \pm 4.34$ & 0.716 \\
Post-PVR, Wood units & $8.05 \pm 3.68$ & $12.02 \pm 8.20$ & 0.359 \\
Post-CO, L/min & $12.46 \pm 7.77$ & $4.87 \pm 1.79$ & $0.85 \pm 3.29$ \\
Post-Cl, L/min/m ${ }^{2}$ & $4.56 \pm 1.58$ & $2.92 \pm 1.21$ & 0.098 \\
Post-SvO $(\%)$ & $2.90 \pm 1.29$ & $61.56 \pm 10.33$ & 0.391 \\
Post-SaO $(\%)$ & $61.44 \pm 10.90$ & $93.20 \pm 5.46$ & $2.89 \pm 1.32$ \\
\hline
\end{tabular}

$\mathrm{Cl}$, cardiac index; CO, cardiac output; DBP, diastolic blood pressure; HR, heart rate; mPAP, mean pulmonary arterial pressure; mPCWP, mean pulmonary capillary wedge pressure; mRAP, mean right atrial pressure; PVR, pulmonary vascular resistance; SBP, systolic blood pressure; $\mathrm{SvO}_{2}$, mixed venous oxygen saturation; $\mathrm{SaO}_{2}$, artery oxygen saturation.

post-mRAP, post-mPAP, and post-PVR were significantly higher in non-survivors, and levels of post-CO, post-CI, post- $\mathrm{SvO}_{2}$, and post- $\mathrm{SaO}_{2}$ were significantly lower in nonsurvivors than in survivors (Figure 2). The post-mPCWP level was also significantly increased in all non-survivors and male non-survivors (Figure 2C). Differences in sex were investigated in the post-AVT parameters between survivors and non-survivors and we found that the post- $\mathrm{SaO}_{2}$ level was lower in male non-survivors than in female nonsurvivors (Figure $2 H$ ).

\section{Comparison of $\triangle A V T$ hemodynamic parameters}

The parameters of $\triangle \mathrm{AVT}$ of male patients were similar to those of female patients (Table 3). And the comparison of $\triangle \mathrm{AVT}$ between survivors and non-survivors is show in Figure 3. In females, the absolute changes of $\triangle \mathrm{mPAP}$ and $\triangle \mathrm{PVR}$ were significantly higher in survivors than in nonsurvivors (Figure $3 B, D$ ) whereas no significant difference was observed in male patients. And $\triangle \mathrm{PVR}$ was higher in male survivors than in female survivors (Figure $3 D$ ). Male survivors demonstrated lower $\triangle \mathrm{CO}$ than female survivors (Figure $3 E$ ). We further discovered the importance of $\triangle \mathrm{PVR} / \mathrm{PVR}$, which is higher among all non-survivors and female non-survivors than among survivors, For survivors, the absolute changes of $\triangle \mathrm{PVR} / \mathrm{PVR}$ in male survivors is higher than that in female survivors (Figure 3I).
Furthermore, $\Delta \mathrm{CI} / \mathrm{CI}$ was higher in male non-survivors than in female non-survivors (Figure 37).

\section{Changes of hemodynamic parameters pre- and post-AVT}

The comparison of parameters pre- and post-AVT for patients is shown in Figure 4. Post-mPAP and post-PVR levels were lower than pre-mPAP and pre-PVR levels, respectively, for all patients and female patients, while post$\mathrm{CO}$, post-CI, and post- $\mathrm{SaO}_{2}$ levels were higher than pre$\mathrm{CO}$, pre-CI, and pre-SaO $\mathrm{O}_{2}$ levels. Post-PVR was lower than the pre-PVR level, and the post-CO and post-CI levels were higher than the pre-CO and pre-CI levels, respectively, for male patients.

\section{Independent prognostic parameters in bemodynamics}

The results of the univariate and multivariate analyses in hemodynamic parameters are shown in Figure 5. In general, pre-CO, post-mPAP, post-SvO $\mathrm{S}_{2}$, and $\triangle \mathrm{PVR}$ levels were associated with patients' prognosis (Figure $5 A, B, C$ ). In multivariate analysis, pre-PVR, pre-SvO ${ }_{2}$, and postmPAP levels were independent predictors for survival of male patients (Figure 5D,E), whereas the pre-mRAP, prePVR, post-PVR, post-SvO ${ }_{2}, \Delta \mathrm{mPAP}, \Delta \mathrm{PVR}$, and $\Delta \mathrm{SvO}_{2}$ parameters were independent predictors for survival of female patients (Figure 5G,H,I). 

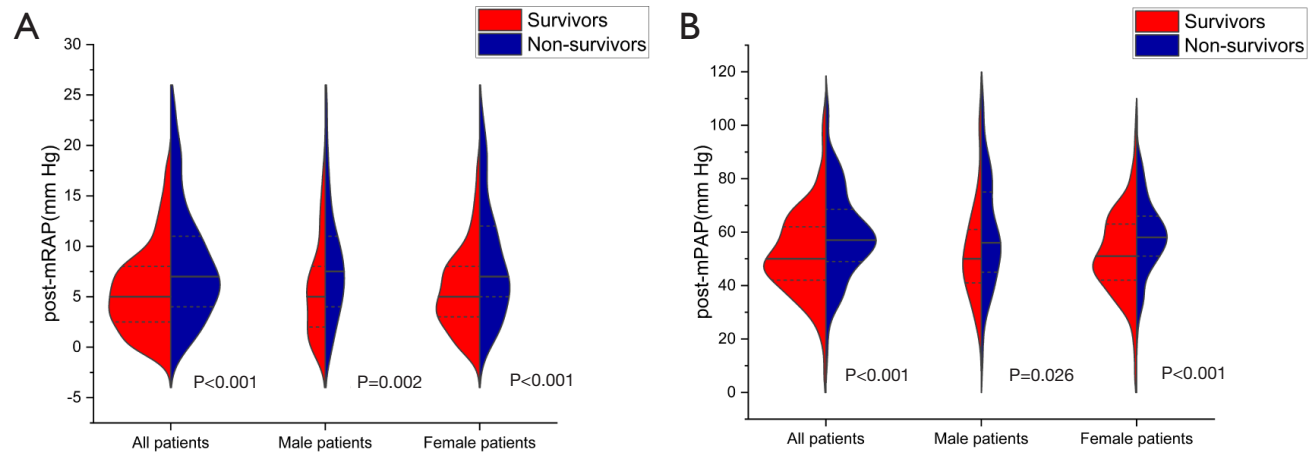

C

Survivors

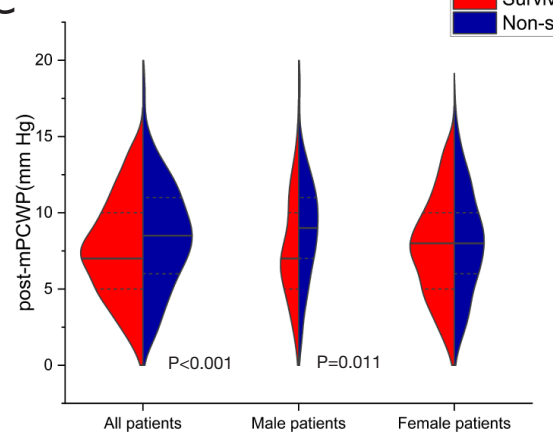

$\mathrm{D}$
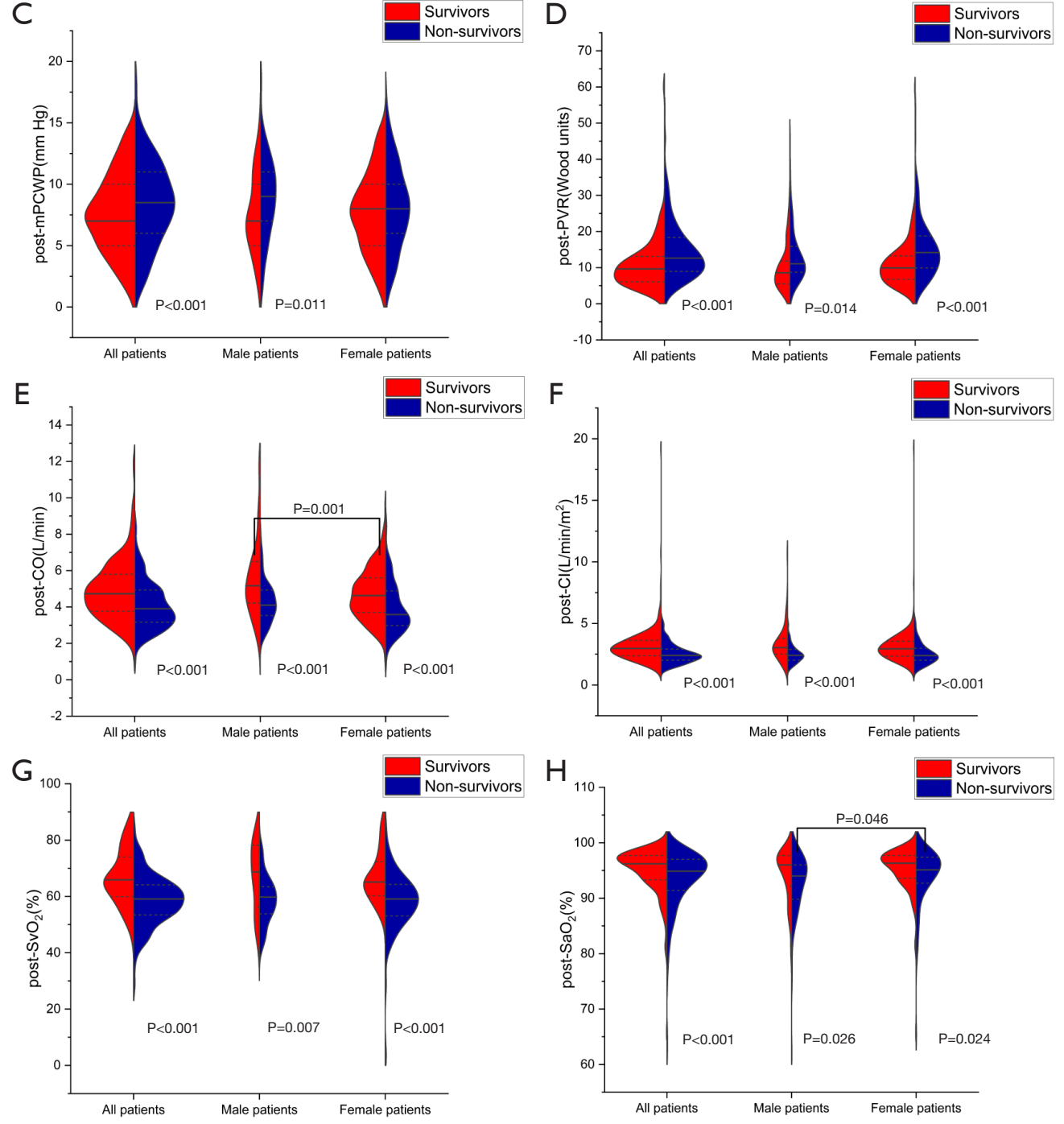

Figure 2 Comparison of the parameters of post-AVT between survivors and non-survivors. (A) Comparison of post-mRAP between survivors and non-survivors; (B) comparison of post-mPAP between survivors and non-survivors; (C) comparison of post-mPCWP between survivors and non-survivors; (D) comparison of post-PVR between survivors and non-survivors; (E) comparison of post-CO between survivors and non-survivors; (F) comparison of post-CI between survivors and non-survivors; (G) comparison of post-SvO $\mathrm{O}_{2}$ between survivors and non-survivors; $(\mathrm{H})$ comparison of post- $\mathrm{SaO}_{2}$ between survivors and non-survivors. AVT, acute vasoreactivity testing; mRAP, mean right atrial pressure; mPCWP, mean pulmonary capillary wedge pressure; PVR, pulmonary vascular resistance; CO, cardiac output; CI, cardiac index; $\mathrm{SvO}_{2}$, mixed venous oxygen saturation; $\mathrm{SaO}_{2}$, artery oxygen saturation. 
Table 3 Changes of hemodynamic parameters of patients with IPAH during acute vasodilator testing $(\mathrm{n}=487)$

\begin{tabular}{|c|c|c|c|c|}
\hline Variable & All patients $(n=487)$ & Males $(n=171)$ & Females $(n=316)$ & $P$ value \\
\hline$\triangle \mathrm{SBP}, \mathrm{mmHg}$ & $-4(-10.00,2.00)$ & $-2.00(-9.00,3.00)$ & $-4.00(-11.00,1.00)$ & 0.124 \\
\hline$\triangle \mathrm{DBP}, \mathrm{mmHg}$ & $-3.00(-7.00,2.00)$ & $-2.00(-6.00,2.00)$ & $-3.00(-8.00,1.00)$ & 0.133 \\
\hline$\triangle \mathrm{mRAP}, \mathrm{mmHg}$ & $0.00(-1.00,1.00)$ & $0.00(-1.00,1.00)$ & $0.00(-1.00,1.00)$ & 0.572 \\
\hline$\triangle \mathrm{mPCWP}, \mathrm{mmHg}$ & $0.00(0.00,1.00)$ & $0.00(-1.00,1.00)$ & $0.00(0.00,1.00)$ & 0.100 \\
\hline$\triangle P V R$, Wood units & $-1.80(-3.49,-0.39)$ & $-1.81(-3.51,-0.46)$ & $-1.79(-3.48,-0.32)$ & 0.787 \\
\hline$\triangle P V R / P V R$ & $-0.15(-0.25,-0.03)$ & $-0.15(-0.29,-0.04)$ & $-0.14(-0.24,-0.03)$ & 0.268 \\
\hline$\Delta \mathrm{CO}, \mathrm{L} / \mathrm{min}$ & $0.36(0.00,0.81)$ & $0.37(0.00,0.96)$ & $0.22(0.00,0.73)$ & 0.314 \\
\hline$\Delta \mathrm{Cl} / \mathrm{Cl}$ & $0.09(0.00,0.22)$ & $0.09(-0.01,0.22)$ & $0.09(-0.01,0.24)$ & 0.363 \\
\hline$\Delta \mathrm{SvO}_{2}(\%)$ & $0.80(-4,4.60)$ & $0.25(-3.43,4.30)$ & $1.00(-4,4.80)$ & 0.564 \\
\hline$\Delta \mathrm{SvO}_{2} / \mathrm{SvO}_{2}$ & $0.01(-0.05,0.08)$ & $0.01(-0.05,0.08)$ & $0.00(-0.06,0.07)$ & 0.481 \\
\hline$\Delta \mathrm{SaO}_{2}(\%)$ & $0.60(-0.70,2.20)$ & $0.60(-0.80,2.00)$ & $0.60(-0.67,2.20)$ & 0.846 \\
\hline $\mathrm{SaO}_{2} / \mathrm{SaO}_{2}$ & $0.00(-0.01,0.02)$ & $0.01(-0.01,0.02)$ & $0.01(-0.01,0.02)$ & 0.902 \\
\hline
\end{tabular}

Values are given as changes $(\Delta)$ during vasodilator testing. $\mathrm{Cl}$, cardiac index; CO, cardiac output; DBP, diastolic blood pressure; HR, heart rate; mPAP, mean pulmonary arterial pressure; mPCWP, mean pulmonary capillary wedge pressure; mRAP, mean right atrial pressure; PVR, pulmonary vascular resistance; $\mathrm{SBP}$, systolic blood pressure; $\mathrm{SvO}_{2}$, mixed venous oxygen saturation; $\mathrm{SaO}_{2}$, artery oxygen saturation.

\section{ROC analysis in patients with IPAH}

ROC analysis was used to evaluate the ability of parameters that had a significant correlation with survival in the multivariate analysis to predict survival. Results are presented in Table 4 and Figure 6. In general, pre-CO $=3.25 \mathrm{~L} / \mathrm{min}$ showed a sensitivity of $55.9 \%$ and a specificity of $80.0 \%$ in predicting survival (Figure $6 A$ ), while post-mRAP $=53 \mathrm{mmHg}$ showed a sensitivity of $68.1 \%$ and a specificity of $56.9 \%$ in predicting survival. In addition, the cut-off value for post-SvO2 was $63.4 \%$ with a sensitivity of $74.8 \%$ and a specificity of $31.1 \%$ (Figure $6 B$ ). In regard to the parameters for male non-survivors, the areas under the curve of prePVR, pre-SvO ${ }_{2}$, and post-mPAP were 0.706, 0.670, and 0.608 , respectively (Figure $6 C, D$ ). The cut-off values were 12.47 Wood units, $64 \%$, and $51 \mathrm{mmHg}$, respectively. PremRAP, pre-PVR, post-PVR, post-SvO ${ }_{2}, \triangle \mathrm{mPAP}$, and $\triangle \mathrm{PVR}$ parameters showed a significant correlation with prognosis, and the initial cut-off values for death prediction were $9.0 \mathrm{mmHg}, 13.65$ Wood units, 13.87 Wood units, 63\%, $-4 \mathrm{mmHg}$, and -0.25 Wood units, respectively
(Figure $6 E, F, G$ ). However, $\Delta \mathrm{SvO}_{2}$ did not show significant correlation with survival in the ROC analysis $(\mathrm{P}=0.354)$.

\section{Prognostic implication of AVT in patients with IPAH}

During the follow-up period (median 46.20, IQR, 18.9085.43 months), 214 ( $\mathrm{n}=487 ; 43.94 \%)$ patients died. The cut-off values of the included parameters for the fraction of survival based on the Kaplan-Meier curve analysis are shown in Figure 7. In general, patients with pre-CO $\geq 3.25 \mathrm{~L} / \mathrm{min}$, post-mPAP $<53 \mathrm{mmHg}$, or post-SvO2 $\geq 63 \%$ had a better prognosis (Figure $7 A, B$ ). Male patients with pre-PVR $<12.47$ Wood units, pre- $\mathrm{SvO}_{2} \geq 64 \%$, and post-mPAP $<51 \mathrm{mmHg}$ had a better prognosis than other male patients (Figure $7 C, D)$. Female patients with pre-mRAP $<9.0 \mathrm{mmHg}$, pre-PVR $<13.65$ Wood units, post-PVR $<13.87$ Wood units, post-SvO $2 \geq 63 \%$, and $\triangle \mathrm{PVR}<-0.25$ Wood units had significantly better outcomes than other female patients (Figure $7 E, F, G$ ). More importantly, an optimal outcome was indicated for those patients who had two prognostic parameters combining at the same time, such as patients 

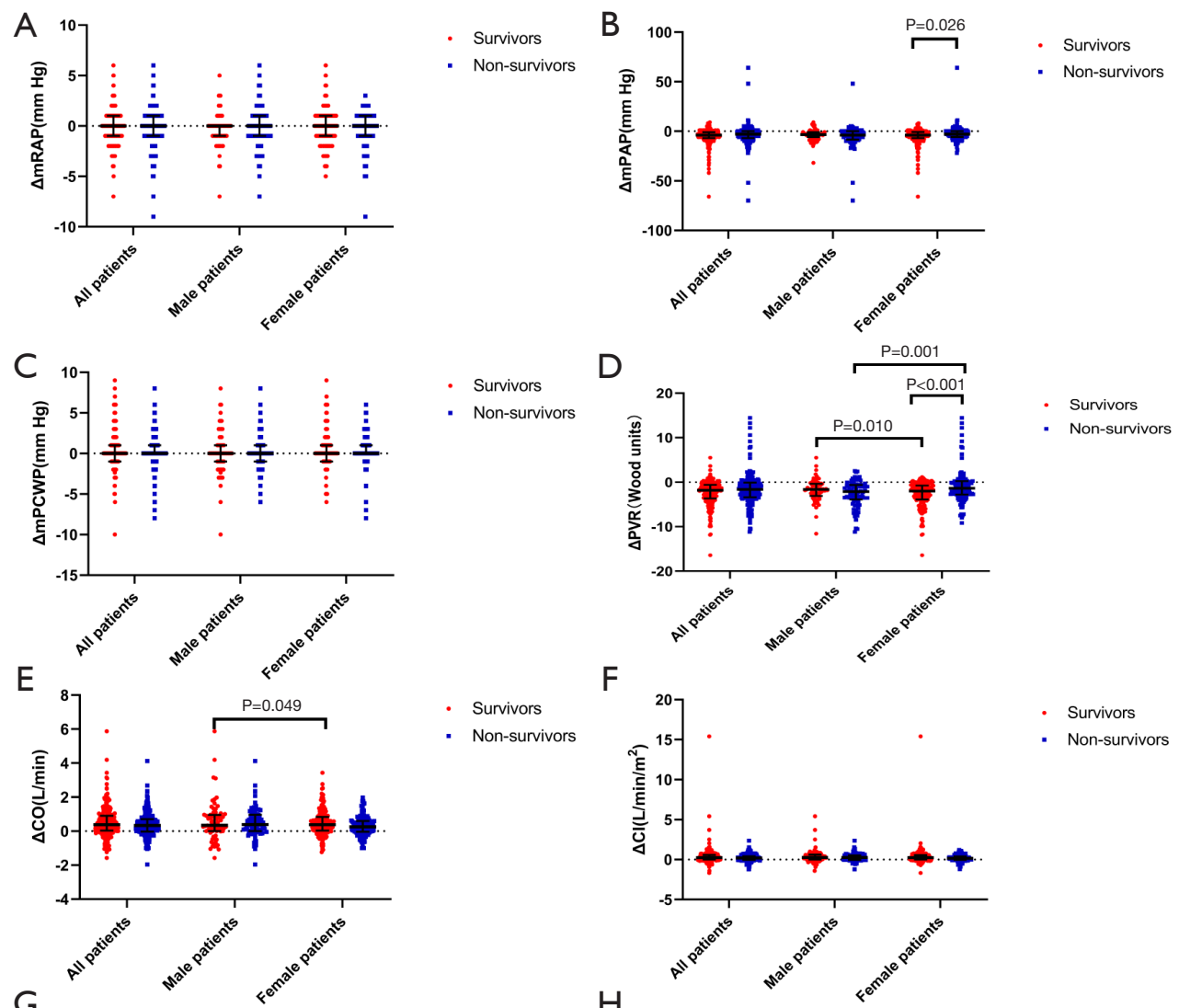

F

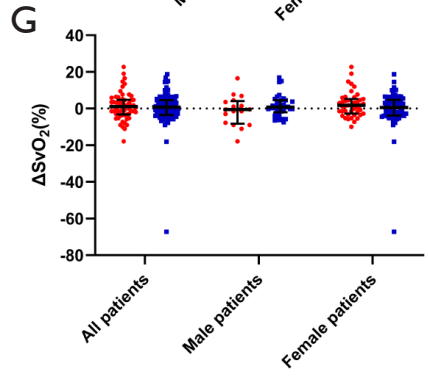

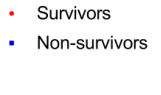

- Survivors

$\mathrm{H}$

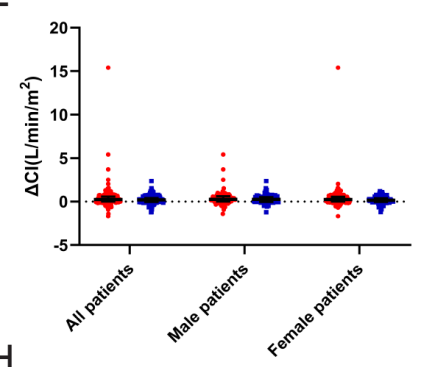

- Survivors

- Non-survivors

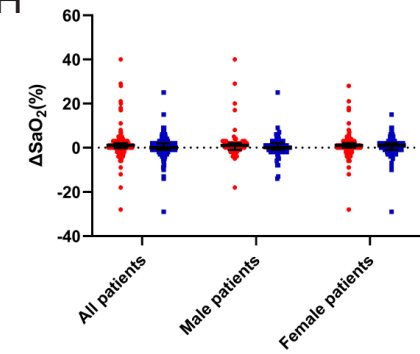

- Survivors

- Non-survivors
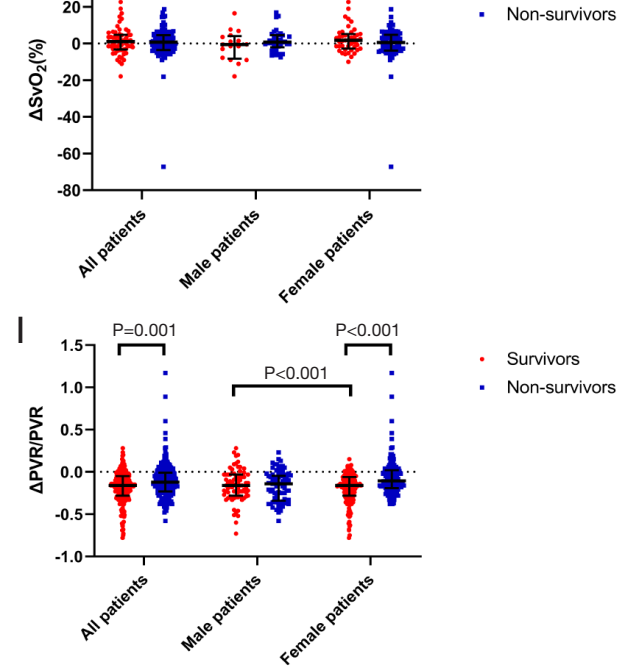

- Survivors

- Non-survivors

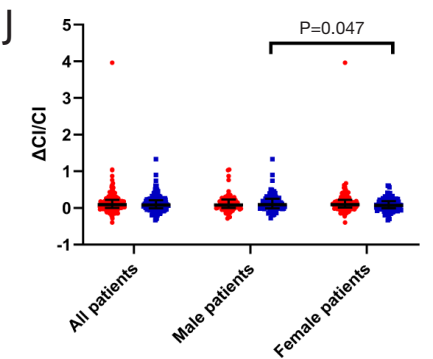

Figure 3 Comparison of $\triangle \mathrm{AVT}$ between survivors and non-survivors. Values are given as changes $(\Delta)$ during vasodilator testing. (A) Comparison of $\triangle$ mRAP between survivors and non-survivors; (B) comparison of $\Delta \mathrm{mPAP}$ between survivors and non-survivors; (C) comparison of $\triangle \mathrm{mPCWP}$ between survivors and non-survivors; (D) comparison of $\triangle \mathrm{PVR}$ between survivors and non-survivors; (E) comparison of $\Delta \mathrm{CO}$ between survivors and non-survivors; (F) comparison of $\Delta \mathrm{CI}$ between survivors and non-survivors; (G) comparison of $\Delta \mathrm{SvO}_{2}$ between survivors and non-survivors; (H) comparison of $\Delta \mathrm{SaO}_{2}$ between survivors and non-survivors; (I) comparison of $\Delta \mathrm{PVR} / \mathrm{PVR}$ between survivors and non-survivors; (J) comparison of $\triangle \mathrm{CI} / \mathrm{CI}$ between survivors and non-survivors. AVT, acute vasoreactivity testing; mRAP, mean right atrial pressure; mPCWP, mean pulmonary capillary wedge pressure; PVR, pulmonary vascular resistance; CO, cardiac output; CI, cardiac index; $\mathrm{SvO}_{2}$, mixed venous oxygen saturation; $\mathrm{SaO}_{2}$, artery oxygen saturation. 

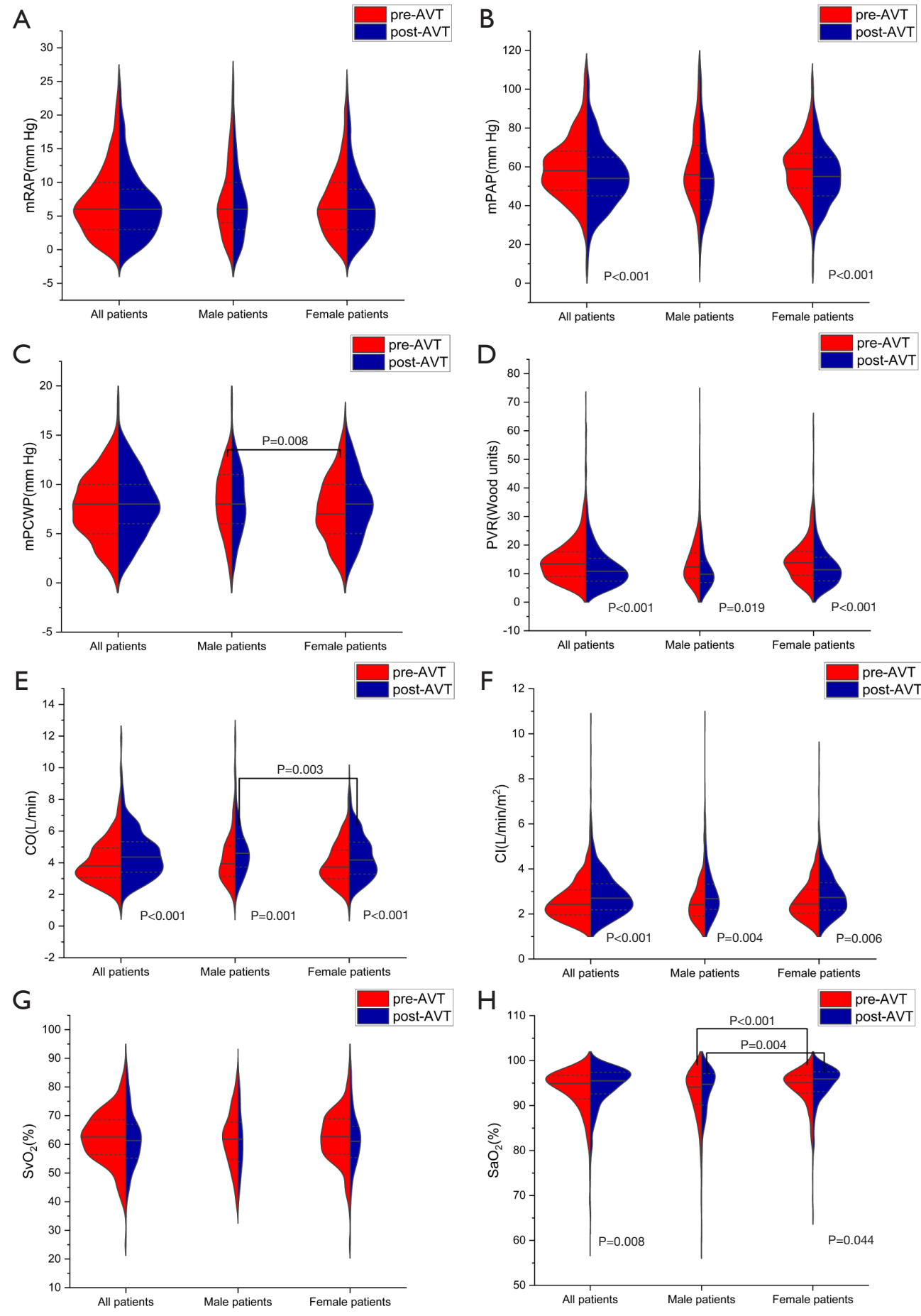

Figure 4 Comparison of the parameters of pre-AVT and post-AVT of patients with IPAH. (A) Comparison of pre-mRAP and post-mRAP of patients with IPAH; (B) comparison of pre-mPAP and post-mPAP of patients with IPAH; (C) comparison of pre-mPCWP and postmPCWP of patients with IPAH; (D) comparison of pre-PVR and post-PVR of patients with IPAH; (E) comparison of pre-CO and post$\mathrm{CO}$ of patients with IPAH; (F) comparison of pre-CI and post-CI of patients with IPAH; $(\mathrm{G})$ comparison of pre-SvO $\mathrm{O}_{2}$ and post-SvO of patients with IPAH; $(\mathrm{H})$ comparison of pre- $\mathrm{SaO}_{2}$ and post- $\mathrm{SaO}_{2}$ of patients with IPAH. AVT, acute vasoreactivity testing; IPAH, idiopathic pulmonary arterial hypertension; mRAP, mean right atrium pressure; mPCWP, mean pulmonary capillary wedge pressure; PVR, pulmonary vascular resistance; $\mathrm{CO}$, cardiac output; CI, cardiac index; $\mathrm{SvO}_{2}$, mixed venous oxygen saturation; $\mathrm{SaO}_{2}$, artery oxygen saturation. 
A

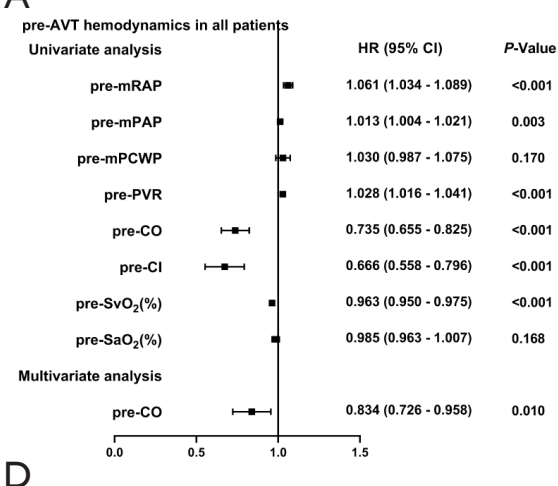

D

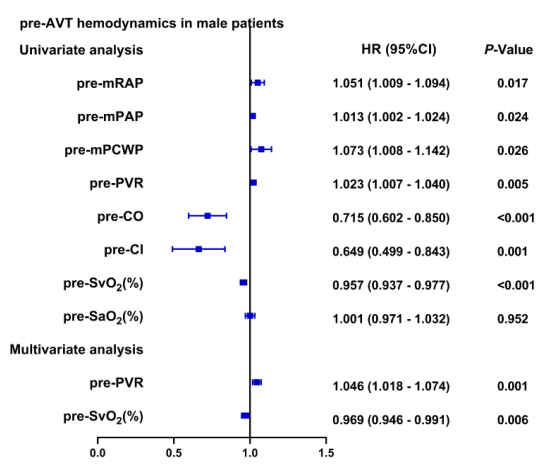

G

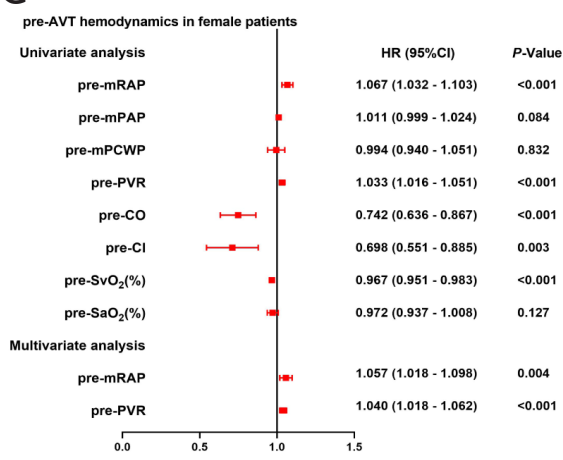

B
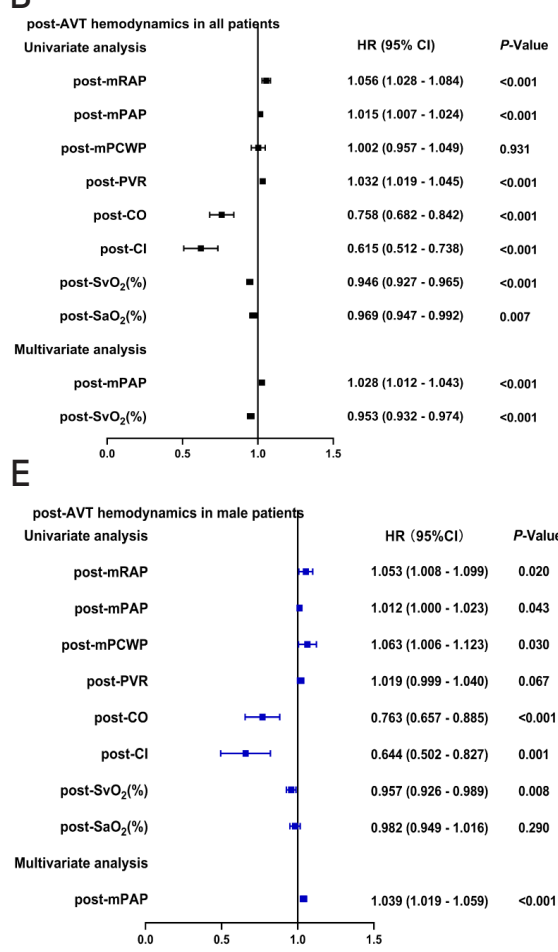

$\mathrm{H}$

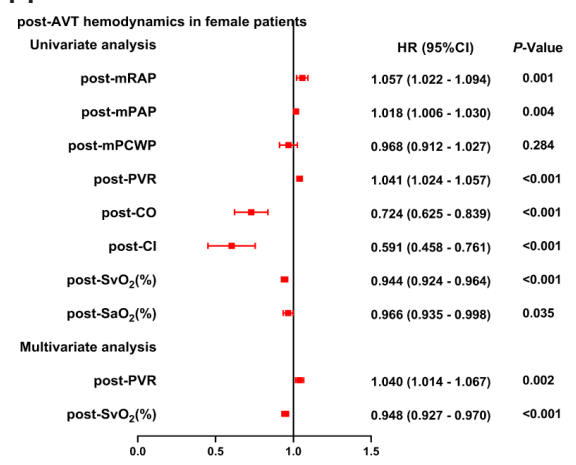

C

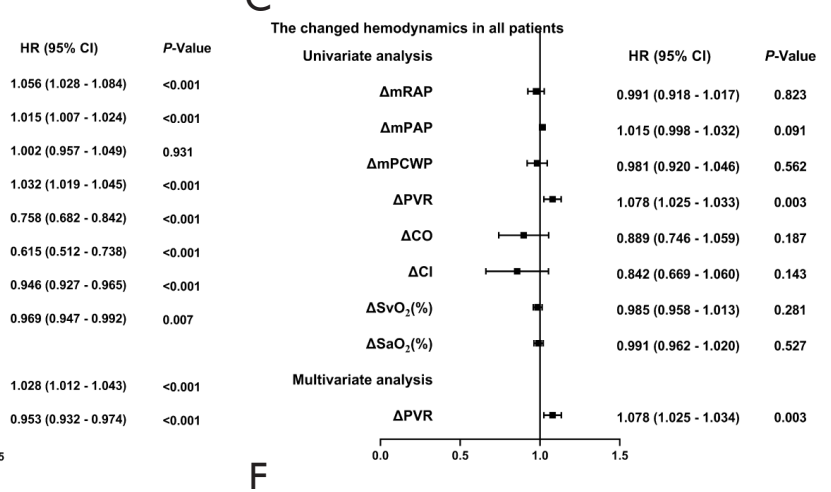

$\mathrm{F}$

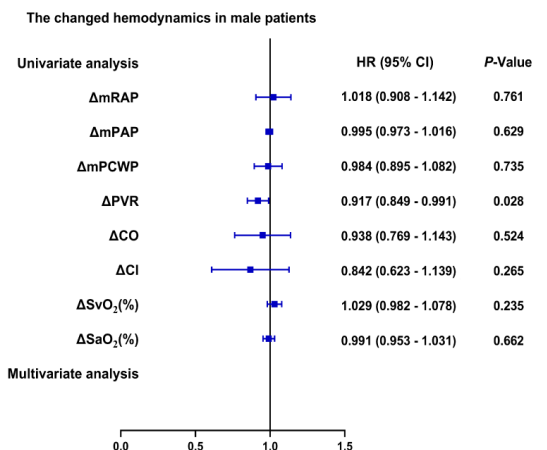

I

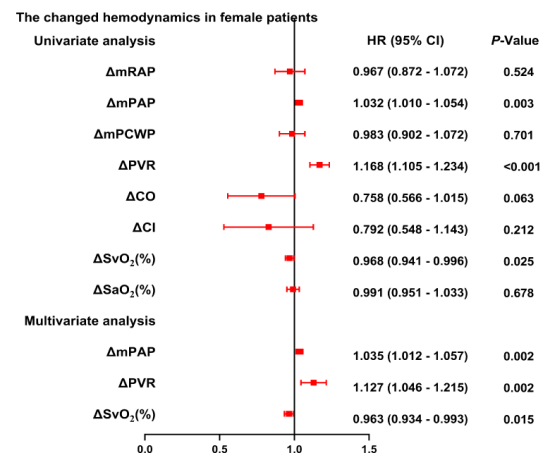

Figure 5 Forest plot showing the univariate and multivariate analyses in hemodynamics. (A) Pre-AVT of all patients with IPAH; (B) postAVT of all patients with IPAH; (C) $\triangle$ AVT of all patients with IPAH; (D) pre-AVT of males with IPAH; (E) post-AVT of males with IPAH; (F) $\triangle$ AVT of males with IPAH; (G) pre-AVT of females with IPAH; (H) post-AVT of females with IPAH; (I) $\triangle$ AVT of females with IPAH. AVT, acute vasoreactivity testing; IPAH, idiopathic pulmonary arterial hypertension.

with their post-mPAP $<53 \mathrm{mmHg}$ and post $-\mathrm{SvO}_{2} \geq 63 \%$, male patients with their pre-PVR $<12.47$ Wood units and pre- $\mathrm{SvO}_{2} \geq 63.6 \%$, or female patients with their pre-mRAP $<9.0 \mathrm{mmHg}$ and pre-PVR $<13.65$ Wood units, or post-PVR $<13.87$ Wood units and post- $\mathrm{SvO}_{2} \geq 63 \%$.

\section{Discussion}

The present study demonstrated that the acute hemodynamic response to iloprost aerosol provided more information than currently used tests in selecting a minority of patients with PAH who can be treated with CCB. We found that post-mPAP and post-PVR indices were lower than pre-mPAP and pre-PVR indices, while post-CO, post-CI, and post- $\mathrm{SaO}_{2}$ levels were higher than pre-CO, pre-CI, and pre $-\mathrm{SaO}_{2}$ levels after AVT for all patients. More importantly, a pre-CO $\geq 3.25 \mathrm{~L} / \mathrm{min}$, a post-mPAP $<53 \mathrm{mmHg}$, and a post- $\mathrm{SvO}_{2} \geq 63 \%$ had a better prognosis 
Table 4 Areas under the ROC curve and the cut-off values of independent predictors for patients with IPAH

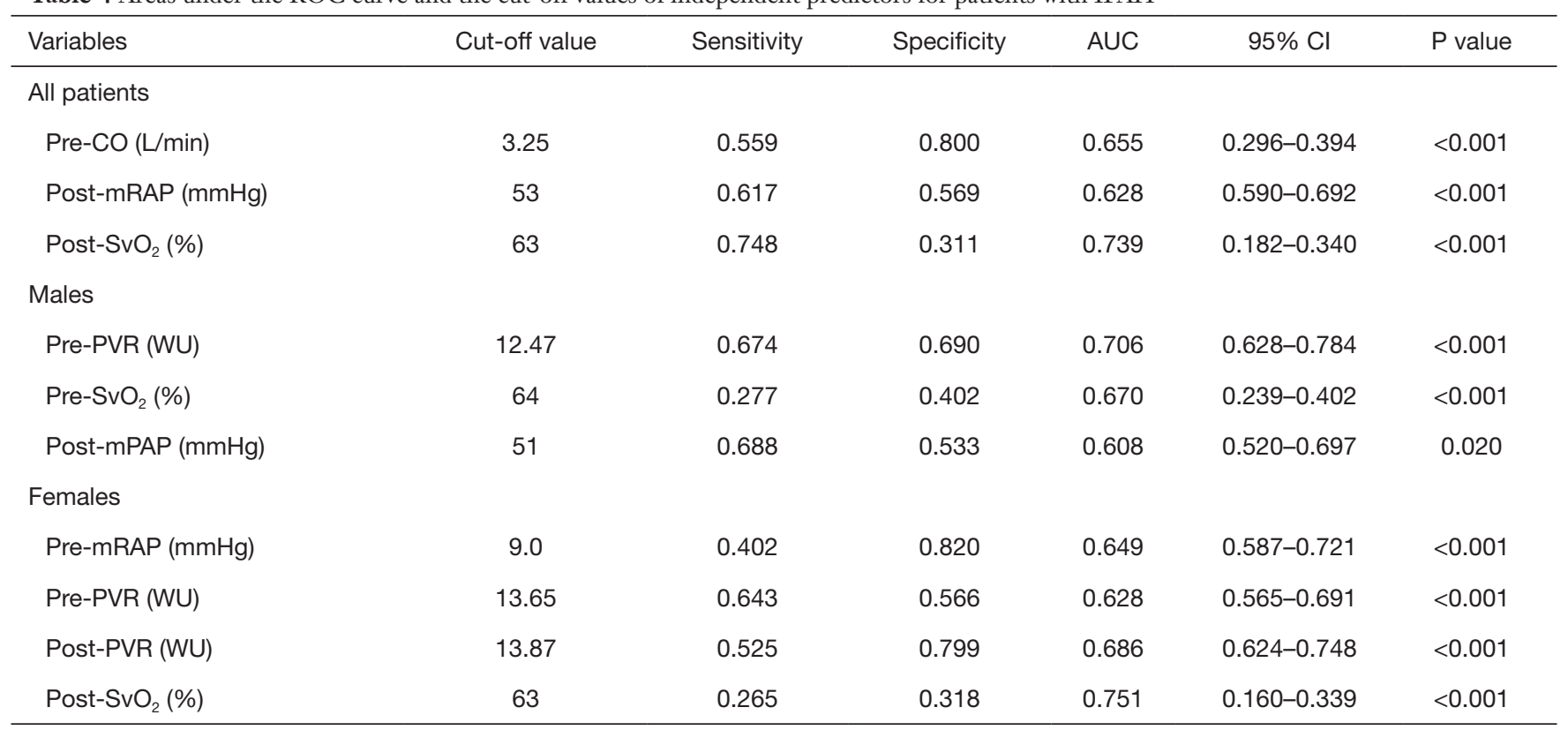

for patients. Pre-PVR $<12.47$ Wood units, pre-SvO $2 \geq 64 \%$, and post-mPAP $<51 \mathrm{mmHg}$ indicated better outcomes for male patients, whereas $\triangle \mathrm{mPAP} \geq-4 \mathrm{mmHg}$ and $\triangle \mathrm{PVR}$ $\geq-0.25$ Wood units indicated better prognosis for female patients. These results may offer an explanation why patients with comparable characteristics have different outcomes during follow-up.

Although IPAH can be managed with targeted drugs (such as endothelin receptor antagonists and prostacyclin inhibitors) which have increased the survival rate of patients with IPAH and improved their outcome, the long-term prognosis of IPAH remains poor (13). Traditionally, IPAH has been considered a disease predominantly affecting women $(14,15)$. Several reasons for the higher female prevalence have been proposed including the role of sex hormones $(16,17)$ and mitochondria (18). Previous studies have suggested that women with IPAH have better survival rates than men $(19,20)$. As the care of patients with IPAH is complex and women with IPAH have a better survival than men, it is important to be able to identify sex-specific prognostic parameters from AVT during RHC.

Our results confirmed the previously hypothesized correlation between a number of baseline hemodynamic parameters, such as higher mRAP, lower CO as well as CI, and worse outcomes (21-23). Other conventionally measured parameters such as mPAP and PVR have been inconsistently related to prognosis $(24,25)$. Our study found that both male and female patients had higher mPAP and PVR levels in non-survivors than in survivors. Furthermore, we found that $\triangle \mathrm{mPAP}$ and $\triangle \mathrm{PVR}$ decreased less in female non-survivors than in female survivors after AVT, whereas there was no significant difference in these parameters between male non-survivors and male survivors. Hemodynamic parameters, including the mPAP and PVR, are related not only to the right ventricular afterload but also to the disease burden in the pulmonary vascular bed $(24,26,27)$. Taken together, these results suggest that women have more vasodilatory reserve than men, which may also account for the better prognosis of female patients.

Subgroup analysis showed that female survivors had significantly higher pre-SaO${ }_{2}$, post-SaO${ }_{2}$, and $\triangle \mathrm{PVR}$ levels than male survivors, and female non-survivors had higher pre- $\mathrm{SaO}_{2}, \Delta \mathrm{CO}$, and $\Delta \mathrm{CO} / \mathrm{CO}$ indices than male nonsurvivors. These results reflect a better reversibility in female patients than male patients, and differs from the sex differences observed in the hemodynamic parameters of AVT in patients with CTEPH as reported in our previous study (8). This might reflect the different pathogenic mechanisms of IPAH and CTEPH where discrete pathophysiological processes could be involved, which may explain this difference in reversibility of the hemodynamic parameters. This also suggests the importance of hemodynamic evaluation in differentiating diseases with similar manifestations. 

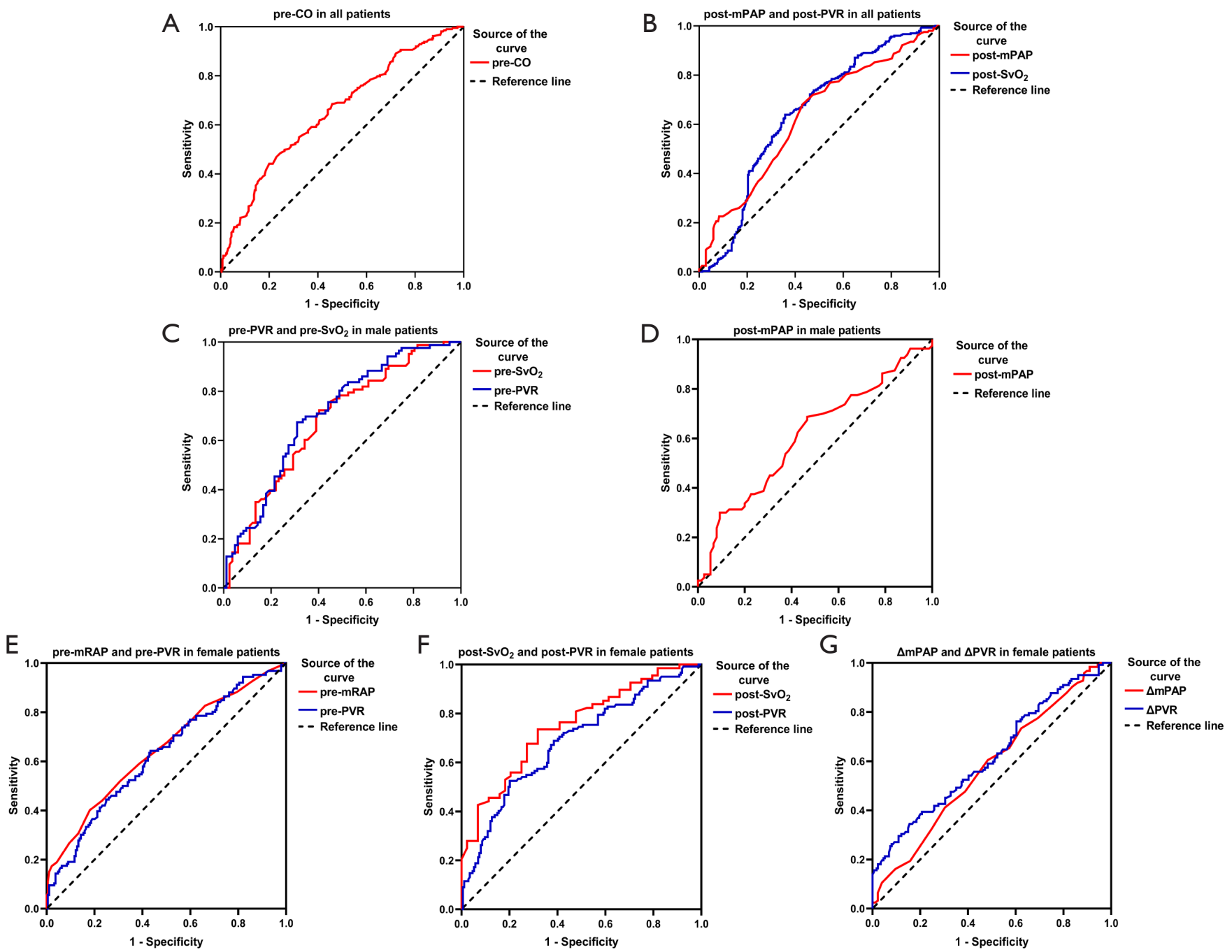

Figure 6 Receiver operating characteristics of patients with IPAH. (A) Pre-CO of all patients with IPAH; (B) post-mPAP and post-PVR of all patients with IPAH; (C) pre-PVR and pre-SvO ${ }_{2}$ of males with IPAH; (D) post-mPAP of males with IPAH; (E) pre-mRAP and pre-PVR of females with IPAH; (F) post-PVR and post-SvO ${ }_{2}$ of females with IPAH; (G) $\triangle$ PVR of females with IPAH. IPAH, idiopathic pulmonary arterial hypertension; $\mathrm{CO}$, cardiac output; mRAP, mean right atrium pressure; PVR, pulmonary vascular resistance; $\mathrm{SvO}_{2}$, mixed venous oxygen saturation; $\mathrm{SaO}_{2}$, artery oxygen saturation.

Many studies have shown the prognostic value of mPAP and CO measures $(20,21,25,28,29)$, and this is in accord with our findings in the present study. In our study, we found that pre-CO $\geq 3.25 \mathrm{~L} / \mathrm{min}$ and post-mPAP $<53$ $\mathrm{mmHg}$ were independent prognostic parameters. In addition, we identified other hemodynamic parameters that were correlated with patient prognosis and these differed according to sex. This might be related to the difference in hormone levels between males and females. Further studies are required to confirm this speculation.

$\mathrm{SvO}_{2}$, a parameter related to oxygen delivery and oxygen consumption, was also hypothesized to be a robust indicator of right ventricular function. It provides important prognostic information in many subsets of $\mathrm{PH}(27,30,31)$. As expected, pre- $\mathrm{SvO}_{2}$ was identified as an independent predictor of non-survival of male patients with IPAH. However, post- $\mathrm{SvO}_{2}$ was also identified as an independent predictor of non-survival of all patients with IPAH. These results were different from those of our previous study which analyzed the hemodynamic parameters of patients with CTEPH according to sex, and which recommended using $\mathrm{SvO}_{2}$ to predict the prognosis of female patients 

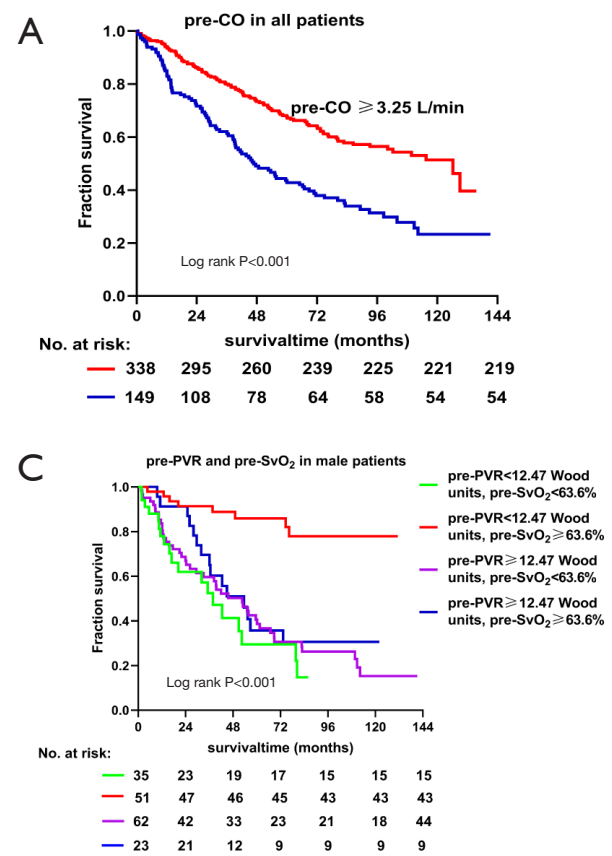
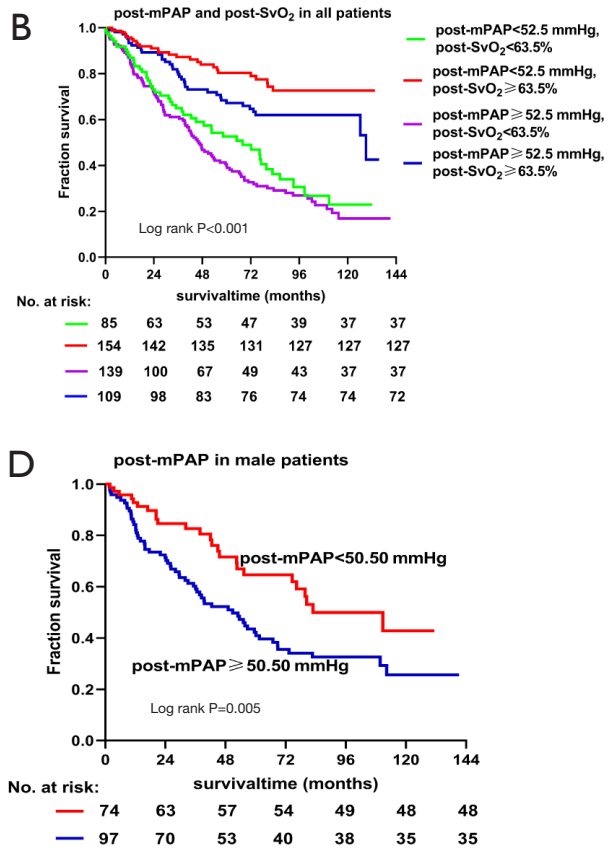

$E$

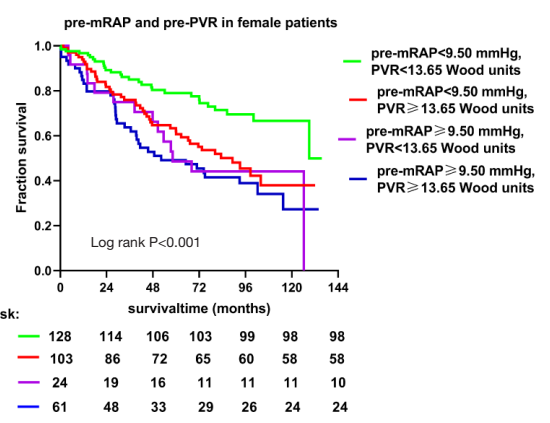

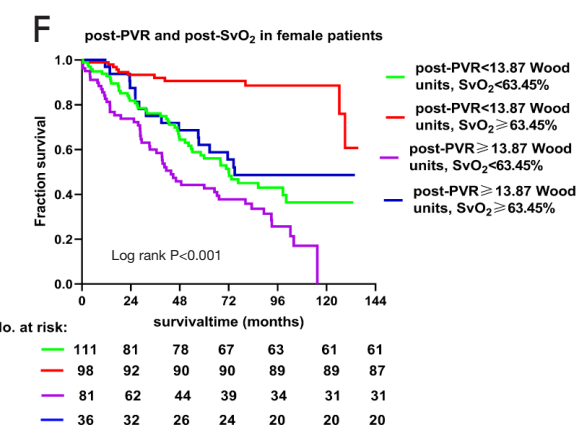

Figure 7 Kaplan-Meier estimates of survival for patients with IPAH. (A) Pre-CO $<3.25 \mathrm{~L} / \mathrm{min}$ and pre-CO $\geq 3.25 \mathrm{~L} / \mathrm{min}$ of all patients; (B) post-mPAP $<52.5 \mathrm{mmHg}$ and post-SvO $\mathrm{S}_{2}<63.5 \%$ with post-mPAP $<52.5 \mathrm{mmHg}$ and post-SvO $2 \geq 63.5 \%$, post-mPAP $\geq 52.5 \mathrm{mmHg}$ and post$\mathrm{SvO}_{2}<63.5 \%$, post-mPAP $\geq 52.5 \mathrm{mmHg}$ and post-SvO $2 \geq 63.5 \%$ of all patients; (C) pre-PVR $<12.47$ Wood units and pre-SvO $<63.6 \%$ with pre-PVR $<12.47$ Wood units and pre-SvO $2363.6 \%$, pre-PVR $\geq 12.47$ Wood units and pre-SvO $\mathrm{S}_{2}<63.6 \%$, pre-PVR $\geq 12.47$ Wood units and pre- $\mathrm{SvO}_{2} \geq 63.6 \%$ of males; (D) post-mPAP $<51 \mathrm{mmHg}$ with post-mPAP $\geq 51 \mathrm{mmHg}$ of males; (E) pre-mRAP $<9.50 \mathrm{mmHg}$ and pre-PVR $<13.65$ Wood units with pre-mRAP $<9.50 \mathrm{mmHg}$ and pre-PVR $\geq 13.65$ Wood units, pre-mRAP $\geq 9.50 \mathrm{mmHg}$ and pre-PVR $<13.65$ Wood units, pre-mRAP $\geq 9.50 \mathrm{mmHg}$ and pre-PVR $\geq 13.65$ Wood units of females; (F) post-PVR $<13.87$ Wood units and post-SvO $\mathrm{O}_{2}<63 \%$ with post-PVR $<13.87$ Wood units and post-SvO $2 \geq 63 \%$, post-PVR $\geq 13.87$ Wood units and post-SvO $<63 \%$, post-PVR $\geq 13.87$ Wood units and post-SvO $2 \geq 63 \%$ of females; (G) $\triangle \mathrm{PVR}<-0.35$ Wood units with $\triangle \mathrm{PVR} \geq-0.35$ Wood units of females. IPAH, idiopathic pulmonary arterial hypertension; $\mathrm{CO}$, cardiac output; mRAP, mean right atrium pressure; $\mathrm{PVR}$, pulmonary vascular resistance; $\mathrm{SvO}_{2}$, mixed venous oxygen saturation; $\mathrm{SaO}_{2}$, artery oxygen saturation.

with CTEPH, and $\triangle \mathrm{SvO}_{2}$ to predict the prognosis of male patients with CTEPH (8). This discrepancy in results might be explained by the different sample sizes of the selected populations and the different type of disease. The etiology of CTEPH includes cancer, inflammation, infection, and other specific clinical conditions underlying the failure of thrombus removal. Thrombotic materials impair blood flow, and ultimately lead to the development of CTEPH (32-34). IPAH is the consequence of the progressive increase in PVR due to pulmonary vasoconstriction and structural changes. Pulmonary vasoconstriction is reversible in response to vasodilators, while chronic remodeling of 
pulmonary vessels is possibly irreversible. Reversibility of pulmonary vasculature is closely related to the severity of the underlying pathology. Therefore, the outcomes for patients with IPAH may depend on the reversibility of the pulmonary vasculature which was directly reflected in the parameters of AVT.

In 2015, Leuchte et al. (6) reported that $\Delta$ PVR during AVT was of prognostic relevance for 66 patients with IPAH who presented with a negative acute response. They found that post-CO, post- $\mathrm{CI}$, and post- $\mathrm{SvO} 2$ parameters were increased, while post-mPAP and post-PVR parameters were decreased after AVT, but the prognostic value of these parameters was not further explored. In our study, we enrolled a total of 487 patients with IPAH who presented with a negative acute response, the sample size was about 7 times larger than their sample size, which obviously reduced the data bias. We analyzed the above parameters, the changing trends of post-CO, post- $\mathrm{CI}$, and post- $\mathrm{SvO} 2$ were consistent with their results. Moreover, we also found that the change of post- $\mathrm{SaO} 2$ was statistically significant after inhalation of iloprost aerosol. In addition, we also performed Kaplan-Meier analysis to confirm whether or not these parameters can predict the survival rate. The data indicated that pre-PVR was an independent predictor of prognosis in both male and female patients. Also, post-PVR $<13.87$ Wood units and $\triangle \mathrm{PVR}<-0.35$ Wood units implied a better prognosis. In our study, $\triangle \mathrm{PVR}$ was associated with prognosis only in female patients, while in the study of Leuchte et al., $\triangle \mathrm{PVR}$ was a prognostic parameter for all patients. This discrepancy may be due to the different demographic, regional attribution and baseline clinical characteristics of patients.

The cut-off values of the independent predictors, which were determined by using the ROC curve, led to marked differences in survival between subgroups divided by these cut-off values. More subgroups were derived when two independent predictors were combined to further evaluate the power of these predictors in estimating outcomes of patients with IPAH. This method of combining predictors might provide more clues about the outcomes of such patients in clinical practice. More importantly, we found that prognostic predictors differed between male and female patients. The previous studies indicated that better baseline hemodynamic parameters, poor prognosis in men compared with women with PAH (19,35). And female sex is associated with a lower prevalence and a better outcome of adult patients with heart failure (36). In addition, myocardial adaptations to increased afterload differ between sexes, with male subjects possessing a greater tendency to develop left ventricular dilatation and hypertrophy during the course of left ventricular dysfunction (37). Therefore, male and female IPAH patients had not the absolutely consistent disease progression and outcomes, which lead to get different prognostic predictors after regression analyses. Additionally, whether sex hormones contribute to this finding in IPAH also needs further research.

\section{Limitation}

There are a number of limitations in the present study. we might have missed responders to other vasodilators such as inhaled nitrous oxide (iNO), rather than the drug we used, However, iloprost aerosol seems to have more pronounced hemodynamic effects on patients with $\mathrm{PAH}$ compared to iNO (38). Secondly, we could have missed responders to higher doses of iloprost aerosol during AVT. However, an iloprost aerosol dosage of $5 \mathrm{mg}$ was considered a standard dose for classical vasoresponders by Jing et al. (39) and has been used in various settings before, so it is less likely that we have missed responders at this dose. Thirdly, the present results were obtained from our single center setting and may reflect some selection bias, although it should be noted that our sample size is far larger than other single-center trials to date.

\section{Conclusions}

Our study demonstrates for the first time that different hemodynamic parameters of pre-AVT, post-AVT, and $\triangle \mathrm{AVT}$ have discrete values in predicting the prognosis of patients with IPAH. Sex differences were identified in these parameters, and indicated that both sexes have their own unique hemodynamic parameters that are able to predict outcome. These results suggest that the sex of the patient should be taken into account when estimating prognosis via AVT in IPAH.

\section{Acknowledgments}

We extend appreciation to the families who participated in this study and to the team facilitating this research.

Funding: This study was supported by grants from the National Natural Science Foundation of China (81870042, 81700045 and 81900050), National Science and Technology Information System of the People's Republic of China (2018YFC1313603), Program of Shanghai Science and 
Technology Committee (201409004100).

\section{Footnote}

Reporting Checklist: The authors have completed the REMARK reporting checklist. Available at http://dx.doi. org/10.21037/atm-20-7339

Data Sharing Statement: Available at http://dx.doi. org/10.21037/atm-20-7339

Conflicts of Interest: All authors have completed the ICMJE uniform disclosure form (available at http://dx.doi. org/10.21037/atm-20-7339). The authors have no conflicts of interest to declare.

Ethical Statement: The authors are accountable for all aspects of the work in ensuring that questions related to the accuracy or integrity of any part of the work are appropriately investigated and resolved. This study complied with the Declaration of Helsinki (as revised in 2013) and was approved by the Medical Ethics Committee of Shanghai Pulmonary Hospital. Written informed consent was obtained from either the patients or their next of kin.

Open Access Statement: This is an Open Access article distributed in accordance with the Creative Commons Attribution-NonCommercial-NoDerivs 4.0 International License (CC BY-NC-ND 4.0), which permits the noncommercial replication and distribution of the article with the strict proviso that no changes or edits are made and the original work is properly cited (including links to both the formal publication through the relevant DOI and the license). See: https://creativecommons.org/licenses/by-ncnd $/ 4.0 \%$.

\section{References}

1. McLaughlin VV, McGoon MD. Pulmonary arterial hypertension. Circulation 2006;114:1417-31.

2. Simonneau G, Montani D, Celermajer DS, et al. Haemodynamic definitions and updated clinical classification of pulmonary hypertension. Eur Respir J 2019;53:1801913.

3. Galie N, Humbert M, Vachiery JL, et al. 2015 ESC/ERS Guidelines for the diagnosis and treatment of pulmonary hypertension: The Joint Task Force for the Diagnosis and Treatment of Pulmonary Hypertension of the European Society of Cardiology (ESC) and the European Respiratory Society (ERS): Endorsed by: Association for European Paediatric and Congenital Cardiology (AEPC), International Society for Heart and Lung Transplantation (ISHLT). Eur Heart J 2016;37:67-119.

4. Galie N, Humbert M, Vachiery JL, et al. 2015 ESC/ERS Guidelines for the diagnosis and treatment of pulmonary hypertension: The Joint Task Force for the Diagnosis and Treatment of Pulmonary Hypertension of the European Society of Cardiology (ESC) and the European Respiratory Society (ERS): Endorsed by: Association for European Paediatric and Congenital Cardiology (AEPC), International Society for Heart and Lung Transplantation (ISHLT). Eur Respir J 2015;46:903-75.

5. Chazova IE, Avdeev SN, Tsareva NA, et al. Clinical guidelines for the diagnosis and treatment of pulmonary hypertension. Ter Arkh 2014;86:4-23.

6. Leuchte HH, Baezner C, Baumgartner RA, et al. Residual pulmonary vasodilative reserve predicts outcome in idiopathic pulmonary hypertension. Heart 2015;101:972-6.

7. Yu YZ, Yuan P, Yang YL, et al. Changed hemodynamics in acute vasoreactivity testing: prognostic predictors in chronic thromboembolic pulmonary hypertension. Am J Transl Res 2020;12:959-73.

8. Yang YL, Yu YZ, Yuan P, et al. Sex differences of hemodynamics during acute vasoreactivity testing to predict the outcomes of chronic thromboembolic pulmonary hypertension. Clin Respir J 2020;14:611-21.

9. Task Force for Diagnosis and Treatment of Pulmonary Hypertension of European Society of Cardiology (ESC); European Respiratory Society (ERS); International Society of Heart and Lung Transplantation (ISHLT); et al. Guidelines for the diagnosis and treatment of pulmonary hypertension. Eur Respir J 2009;34:1219-63.

10. Shigeta A, Tanabe N, Shimizu H, et al. Gender differences in chronic thromboembolic pulmonary hypertension in Japan. Circ J 2008;72:2069-74.

11. Yuan P, Ni HJ, Chen TX, et al. Sex-specific cardiopulmonary exercise testing parameters as predictors in patients with idiopathic pulmonary arterial hypertension. Hypertens Res 2017;40:868-75.

12. Wang L, Jin YZ, Zhao QH, et al. Hemodynamic and gas exchange effects of inhaled iloprost in patients with COPD and pulmonary hypertension. Int J Chron Obstruct Pulmon Dis 2017;12:3353-60.

13. Emanuel R, Chichra A, Patel N, et al. Neurohormonal 
modulation as therapeutic avenue for right ventricular dysfunction in pulmonary artery hypertension: till the dawn, waiting. Ann Transl Med 2018;6:301.

14. Badesch DB, Raskob GE, Elliott CG, et al. Pulmonary arterial hypertension: baseline characteristics from the REVEAL Registry. Chest 2010;137:376-87.

15. Humbert M, Sitbon O, Chaouat A, et al. Pulmonary arterial hypertension in France: results from a national registry. Am J Respir Crit Care Med 2006;173:1023-30.

16. Foderaro A, Ventetuolo CE. Pulmonary Arterial Hypertension and the Sex Hormone Paradox. Curr Hypertens Rep 2016;18:84.

17. Mair KM, Wright AF, Duggan N, et al. Sexdependent influence of endogenous estrogen in pulmonary hypertension. Am J Respir Crit Care Med 2014;190:456-67.

18. Marshall JD, Bazan I, Zhang Y, et al. Mitochondrial dysfunction and pulmonary hypertension: cause, effect, or both. Am J Physiol Lung Cell Mol Physiol 2018;314:L782-96.

19. Shapiro S, Traiger GL, Turner M, et al. Sex differences in the diagnosis, treatment, and outcome of patients with pulmonary arterial hypertension enrolled in the registry to evaluate early and long-term pulmonary arterial hypertension disease management. Chest 2012;141:363-73.

20. Weatherald J, Boucly A, Chemla D, et al. Prognostic Value of Follow-Up Hemodynamic Variables After Initial Management in Pulmonary Arterial Hypertension. Circulation 2018;137:693-704.

21. Humbert M, Sitbon O, Chaouat A, et al. Survival in patients with idiopathic, familial, and anorexigenassociated pulmonary arterial hypertension in the modern management era. Circulation 2010;122:156-63.

22. Campo A, Mathai SC, Le Pavec J, et al. Hemodynamic predictors of survival in scleroderma-related pulmonary arterial hypertension. Am J Respir Crit Care Med 2010;182:252-60.

23. Saggar R, Sitbon O. Hemodynamics in pulmonary arterial hypertension: current and future perspectives. Am J Cardiol 2012;110:9S-15S.

24. McLaughlin VV, Shillington A, Rich S. Survival in primary pulmonary hypertension: the impact of epoprostenol therapy. Circulation 2002;106:1477-82.

25. Benza RL, Miller DP, Gomberg-Maitland M, et al. Predicting survival in pulmonary arterial hypertension: insights from the Registry to Evaluate Early and LongTerm Pulmonary Arterial Hypertension Disease
Management (REVEAL). Circulation 2010;122:164-72.

26. Shapiro S, Traiger GL, Turner M, et al. Sex differences in the diagnosis, treatment, and outcome of patients with pulmonary arterial hypertension enrolled in the registry to evaluate early and long-term pulmonary arterial hypertension disease management. Chest 2012;141:363-73.

27. Sitbon O, Humbert $M$, Nunes H, et al. Long-term intravenous epoprostenol infusion in primary pulmonary hypertension: prognostic factors and survival. J Am Coll Cardiol 2002;40:780-8.

28. McLaughlin VV, Gaine SP, Howard LS, et al. Treatment goals of pulmonary hypertension. J Am Coll Cardiol 2013;62:D73-81.

29. Vonk Noordegraaf A, Westerhof BE, Westerhof N. The Relationship Between the Right Ventricle and its Load in Pulmonary Hypertension. J Am Coll Cardiol 2017;69:236-43.

30. McLaughlin VV, Sitbon O, Badesch DB, et al. Survival with first-line bosentan in patients with primary pulmonary hypertension. Eur Respir J 2005;25:244-9.

31. Sitbon O, McLaughlin VV, Badesch DB, et al. Survival in patients with class III idiopathic pulmonary arterial hypertension treated with first line oral bosentan compared with an historical cohort of patients started on intravenous epoprostenol. Thorax 2005;60:1025-30.

32. Lang IM, Dorfmuller P, Vonk Noordegraaf A. The Pathobiology of Chronic Thromboembolic Pulmonary Hypertension. Ann Am Thorac Soc 2016;13 Suppl 3:S215-21.

33. Banks DA, Pretorius GV, Kerr KM, et al. Pulmonary endarterectomy: part I. Pathophysiology, clinical manifestations, and diagnostic evaluation of chronic thromboembolic pulmonary hypertension. Semin Cardiothorac Vasc Anesth 2014;18:319-30.

34. Wagenvoort CA. Pathology of pulmonary thromboembolism. Chest 1995;107:10S-7S.

35. Barbro K, Magnus N, David K, et al. Sex-specific differences and survival in patients with idiopathic pulmonary arterial hypertension 2008-2016. ERJ Open Res 2019;5:00075-2019.

36. Melissa RD, Paramjit ST, Naranjan SD. Gender differences in cardiac dysfunction and remodeling due to volume overload. J Card Fail 2010;16:439-49.

37. Luchner A, Bröckel U, Muscholl M, et al. Genderspecific differences of cardiac remodeling in subjects with left ventricular dysfunction: a population-based study. Cardiovasc Res 2002;53:720-7. 
38. Pulido T, Adzerikho I, Channick RN, et al. Macitentan and morbidity and mortality in pulmonary arterial hypertension. N Engl J Med 2013;369:809-18.

39. Jing ZC, Jiang X, Han ZY, et al. Iloprost for pulmonary

Cite this article as: Sun Y, Li Y, Meng X, Jiang R, Zhao Q, Wang L, Shi L, Luo C, Qiu H, Wu W, Li J, He J, Liu J, Yuan P, Gong S. Acute vasoreactivity testing predicts outcome of idiopathic pulmonary arterial hypertension patients with a negative acute response. Ann Transl Med 2020;8(24):1650. doi: 10.21037/atm-20-7339 vasodilator testing in idiopathic pulmonary arterial hypertension. Eur Respir J 2009;33:1354-60.

(English Language Editor: D. Fitzgerald) 